Revue des patrimoines

6 | 2005

Patrimoine en situation : l'Inventaire général entre histoire et prospective

\title{
La preuve par le nombre
}

\section{Hélène Verdier}

\section{(2) OpenEdition \\ Journals}

Édition électronique

URL : http://journals.openedition.org/insitu/2535

DOI : $10.4000 /$ insitu.2535

ISSN : 1630-7305

Éditeur

Ministère de la culture

Référence électronique

Hélène Verdier, «La preuve par le nombre », In Situ [En ligne], 6 | 2005, mis en ligne le 24 avril 2012,

consulté le 05 mai 2019. URL : http://journals.openedition.org/insitu/2535 ; DOI : 10.4000/insitu.2535

Ce document a été généré automatiquement le 5 mai 2019.

\section{(c) $(1) \Theta \Theta$}

In Situ Revues des patrimoines est mis à disposition selon les termes de la licence Creative Commons Attribution - Pas d'Utilisation Commerciale - Pas de Modification 4.0 International. 


\title{
La preuve par le nombre
}

\author{
Hélène Verdier
}

1 S'il en était besoin, la question des usages et de la finalité des résultats de l'inventaire général pourrait être abordée par le nombre: nombre d'œuvres répertoriées, de communes inventoriées, de clichés photographiques réalisés, de dossiers, de consultations des notices dans les bases de données... Les additions aujourd'hui sont éloquentes, mais elles laissent dans l'ombre le rôle de l'inventaire qui, en mettant en œuvre une démarche systématique de connaissance, participe à l' identification du patrimoine en devenir et à une re-connaissance sociale de l'existant. On a pu mesurer combien ce préalable est important et participe à la conservation de ce qu'une société doit transmettre, au même titre que les mesures politiques et réglementaires. 
Figure 1

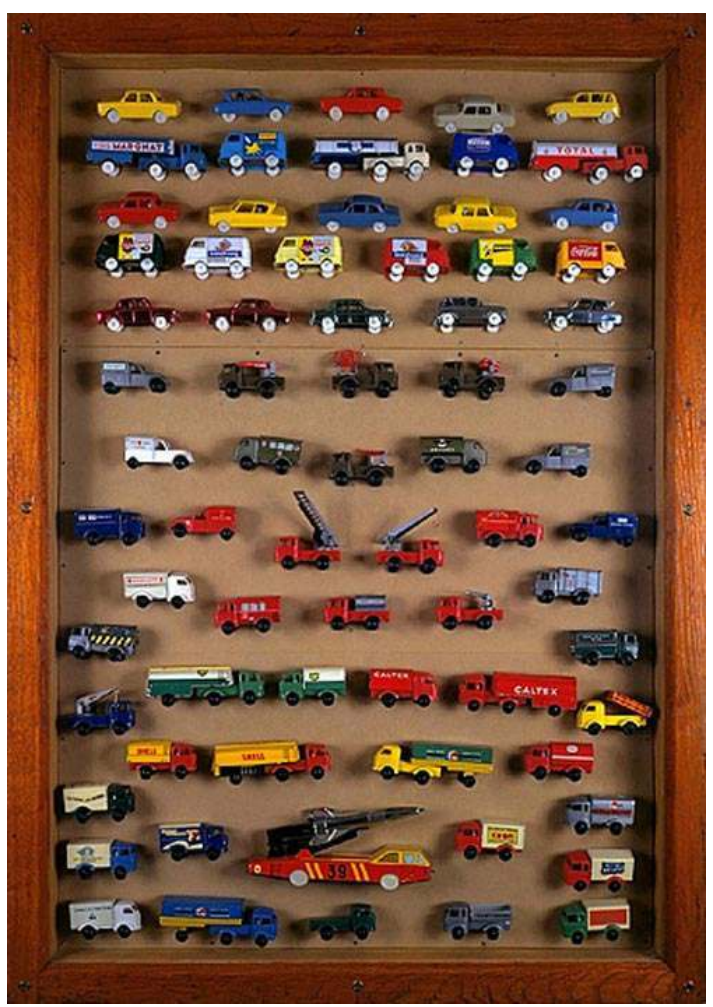

Saint-Claude (Jura). Vitrine de l'usine d'emboutissage Sésame

Phot. Inv. J. Mongreville @ Inventaire général, ADAGP, 1992

2 Les articles réunis dans ce chapitre se situent aussi dans un autre registre: celui des résultats scientifiques du travail. Quels sont les éléments nouveaux que peut apporter une enquête topographique ou thématique? Les méthodes employées : analyses statistique, typologique, technique, stylistique, le croisement des disciplines, histoire, histoire de l'art, archéologie, urbanisme, géographie, ethnologie, permettent, au-delà des clichés, de caractériser un territoire, une catégorie d'œuvres, le travail d'un artiste ou d'un artisan à différentes échelles territoriales - de la banlieue aux contours de l'hexagone- de dessiner des micro ou des macro-frontières jusqu'alors invisibles. Elles permettent de distinguer mais aussi de comparer l'un et le multiple, l'ordinaire et l'exceptionnel, mais aussi d'ouvrir de nouvelles pistes de recherche, preuve de la justesse de l'intention des fondateurs.

\section{AUTEUR}

\section{HÉLÈNE VERDIER}

Conservatrice du patrimoine. Sous-direction de l'archéologie, de l'ethnologie, de l'inventaire et du système d'information. helene.verdier@culture.gouv.fr 